\title{
Histamine-releasing factor has a proinflammatory role in mouse models of asthma and allergy
}

\author{
Jun-ichi Kashiwakura, ${ }^{1,2}$ Tomoaki Ando, ${ }^{1}$ Kenji Matsumoto, ${ }^{3}$ Miho Kimura, ${ }^{1}$ Jiro Kitaura, ${ }^{1}$ \\ Michael H. Matho, ${ }^{1}$ Dirk M. Zajonc, ${ }^{1}$ Tomomitsu Ozeki, ${ }^{4}$ Chisei Ra, ${ }^{2}$ Susan M. MacDonald, ${ }^{5}$ \\ Reuben P. Siraganian, ${ }^{6}$ David H. Broide, ${ }^{7}$ Yuko Kawakami, ${ }^{1}$ and Toshiaki Kawakami'
}

${ }^{1}$ Division of Cell Biology, La Jolla Institute for Allergy and Immunology, La Jolla, California, USA. ²Division of Molecular Cell Immunology and Allergology, Advanced Medical Research Center, Nihon University Graduate School of Medical Science, Tokyo, Japan. ${ }^{3}$ Department of Allergy and Immunology, National Research Institute for Child Health and Development, Tokyo, Japan. ${ }^{4}$ ULVAC Inc., Chigasaki, Japan. 5Johns Hopkins Asthma and Allergy Center, Baltimore, Maryland, USA. ${ }^{6}$ Receptors and Signal Transduction Section, OIIB, National Institute for Dental and Craniofacial Research, NIH, Bethesda, Maryland, USA. ${ }^{7}$ Department of Medicine, UCSD, La Jolla, California, USA.

\begin{abstract}
IgE-mediated activation of mast cells and basophils underlies allergic diseases such as asthma. Histaminereleasing factor (HRF; also known as translationally controlled tumor protein [TCTP] and fortilin) has been implicated in late-phase allergic reactions (LPRs) and chronic allergic inflammation, but its functions during asthma are not well understood. Here, we identified a subset of IgE and IgG antibodies as HRF-interacting molecules in vitro. HRF was able to dimerize and bind to Igs via interactions of its $\mathrm{N}$-terminal and internal regions with the Fab region of Igs. Therefore, HRF together with HRF-reactive IgE was able to activate mast cells in vitro. In mouse models of asthma and allergy, Ig-interacting HRF peptides that were shown to block $\mathrm{HRF} / \mathrm{Ig}$ interactions in vitro inhibited IgE/HRF-induced mast cell activation and in vivo cutaneous anaphylaxis and airway inflammation. Intranasally administered HRF recruited inflammatory immune cells to the lung in naive mice in a mast cell- and Fc receptor-dependent manner. These results indicate that HRF has a proinflammatory role in asthma and skin immediate hypersensitivity, leading us to suggest HRF as a potential therapeutic target.
\end{abstract}

\section{Introduction}

Mast cells and basophils are key effector cells for IgE-dependent allergic inflammatory reactions (1). Upon activation, these cells secrete preformed proinflammatory chemical mediators (e.g., histamine, proteases, proteoglycans, and nucleotides) as well as de novo synthesized lipids (e.g., leukotrienes and prostaglandins) and polypeptides (e.g., cytokines and chemokines). These substances lead to the development of allergic inflammation.

Since Thueson et al. first described an activity from cultured peripheral blood mononuclear cells that induced the release of histamine from basophils (2), histamine-releasing activities have been studied for more than 30 years (3). In addition to several cytokines and chemokines with this activity, an unrelated protein termed histamine-releasing factor (HRF) was purified and molecularly cloned in 1995 (4). HRF, also known as translationally controlled tumor protein (TCTP) and fortilin, is a highly conserved protein with both intracellular and extracellular functions (4-8). HRF is secreted by macrophages and other cell types and can stimulate histamine release and IL-4 and IL-13 production from IgE-sensitized basophils and mast cells (9). HRF-like activities were found in nasal, skin blister, and bronchoalveolar lavage (BAL) fluids during late-phase allergic reactions (LPRs), implicating HRF in the LPR and chronic allergic inflammation (10-12). However, definitive evidence for the role of HRF in allergic reactions has been elusive $(8,9,13)$.

Authorship note: Jun-ichi Kashiwakura and Tomoaki Ando contributed equally to this work.

Conflict of interest: Tomomitsu Ozeki is employed by ULVAC Inc.

Citation for this article: J Clin Invest. 2012;122(1):218-228. doi:10.1172/JCI59072.
Confounding the research, HRF has a wide range of intracellular functions, including cell cycle progression, proliferation, survival, and malignant transformation of a variety of cell types (8). HRF is ubiquitously expressed in all tested eukaryotic cells; its expression is active in mitotically active tissues $(14,15)$ and subject to both transcriptional and translational control (16). In tumor cells, HRF is highly expressed and downregulated upon tumor reversion (17). It is involved in the elongation step of protein synthesis by interacting with both eEF1A (a small GTPase) and eEF1B $\beta$ (a guanine nucleotide exchange factor) (18-20). Drosophila and human HRFs act as the guanine nucleotide exchange factor for the Ras superfamily GTPase, Rheb, which regulates the TSC1-TSC2-mTOR pathway $(21,22)$. These studies implicate this protein in the regulation of growth and proliferation as well as in the control of organ size. HRF interacts with Mcl-1 $(23,24)$ and Bcl-xL (25), antiapoptotic members of the Bcl-2 family, and antagonizes apoptosis by inserting into the mitochondrial membrane and inhibiting Bax dimerization (26). HRF also interacts with p53 tumor suppressor and suppresses p53-mediated apoptosis (27). Other HRF-interacting molecules include tubulin (28), NEMO (29) and vitamin $\mathrm{D}_{3}$ receptor (30). Phosphorylation of HRF by the protein kinase Plk decreases the microtubule-stabilizing activity of HRF (31).

The extracellular function of HRF is considered a cytokine-like activity toward IgE-primed mast cells and basophils (9). Despite considerable efforts, researchers have failed to identify an HRF receptor. Unfortunately, HRF knockout mice are embryonic lethal $(32,33)$ and cannot provide meaningful information on HRF function. Because of the lack of reagents that can distinguish between HRF's intracellular and extracellular functions, it is particularly dif- 

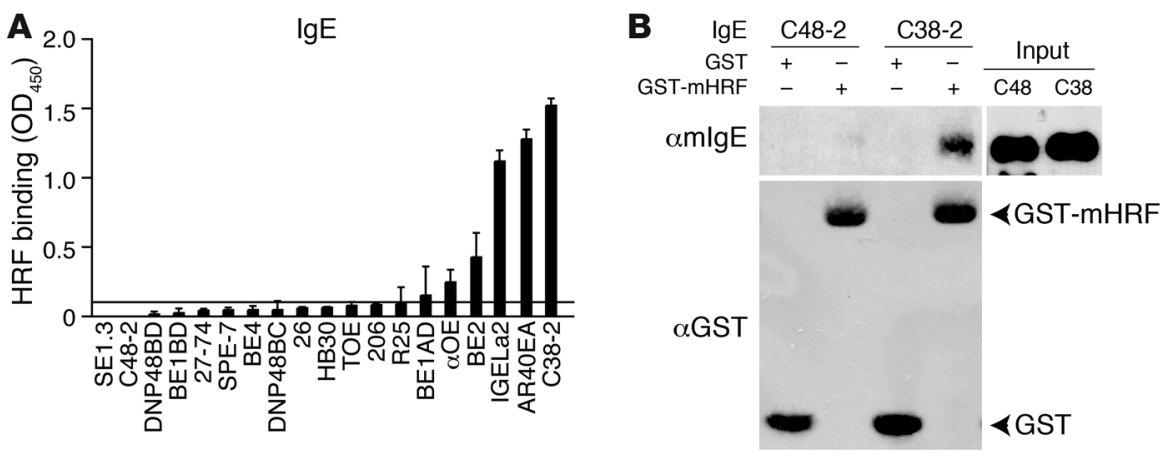

C
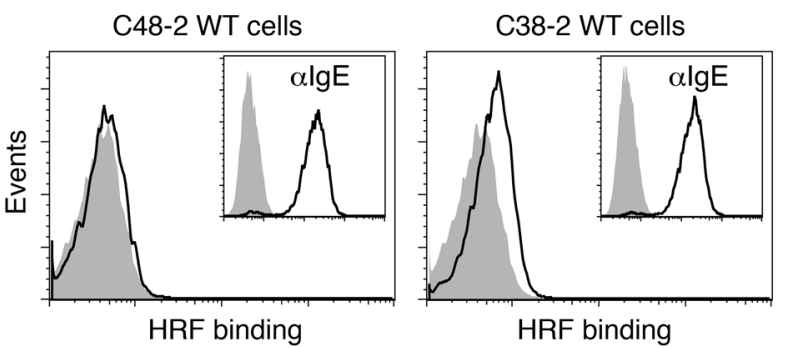

HRF binding

$\lg G$

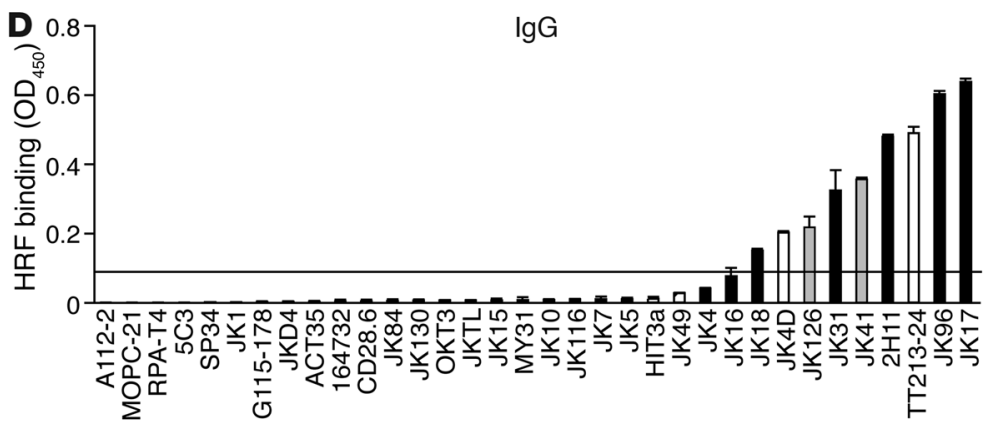

Figure 1

A subset of IgE and IgG molecules binds HRF. (A) IgE molecules were incubated in GST-mHRFcoated wells. HRF-bound IgE was quantified by ELISA, as detected by color development with HRP. $\mathrm{OD}_{450}$ values with GST-mHRF subtracted from those with GST control are shown. $\mathrm{OD}_{450} \leq 0.1$ was used as an arbitrary cutoff value. Data represent at least 3 experiments. (B) IgEs were incubated with GST- or GST-mHRF-agarose beads. Bead-bound IgEs were pulled down. IgE and GST proteins were detected by immunoblotting. Lanes were run on the same gel but were noncontiguous (white lines). Representative of 2 experiments. (C) BMMCs preincubated with (black line) or without (gray shading) the indicated IgE (see Supplemental Table 3) were incubated with $\mathrm{mHRF} \mathrm{His}_{6}$, and bound mHRF-His ${ }_{6}$ was detected with rabbit anti-His tag antibody and Alexa Fluor 647-conjugated anti-rabbit IgG. HRF binding was detected by flow cytometry. Insets show IgE binding: the same cells were incubated with FITC-labeled anti-mouse IgE. Representative of 2 experiments. (D) HRF-bound IgGs were detected by ELISA. Representative of 3 experiments. HRF binding was independent of IgG isotype, as the tested IgG1, IgG2a, and IgG2b molecules contained both HRF-reactive and -nonreactive molecules. The $K_{D}$ values for HRF binding were $0.685 \mu \mathrm{M}$ (JK17), $2.78 \mu \mathrm{M}$ (JK31), and 5.78 $\mu \mathrm{M}$ (JK96). Black bars, IgG1; white bars, IgG2a; gray bars, IgG2b.

ficult to dissect extracellular functions in complex in vivo settings. In this study, we sought to identify HRF-interacting molecules and inhibitors of interactions of HRF with HRF-reactive molecules.

\section{Results}

HRF binds to Fab fragments of a subset of IgE and IgG antibodies. Despite a previous study implying that IgE does not interact with HRF (34), we reexamined this possibility first by using an ELISA and a panel of IgE mAbs. As shown in Figure $1 \mathrm{~A}$, immobilized $\mathrm{N}$-terminally glutathione S-transferase-tagged (GSTtagged) mouse HRF protein (referred to herein as GST-mHRF) bound C38-2 and 5 other IgE mAbs. In contrast, C48-2 and 12 other IgE mAbs failed to bind GST-mHRF. Similar results were obtained when C-terminally hexahistidine-tagged mHRF (referred to herein as mHRF-His $_{6}$ ) was used as a capturing agent (Supplemental Figure 1; supplemental material available online with this article; doi:10.1172/JCI59072DS1). Interaction of C38-2 and IGELa2 IgE mAbs with mHRF was also demonstrated by affinity pulldown (Figure $1 \mathrm{~B}$ and data not shown). HRF bound to mouse bone marrow-derived mast cells (BMMCs) preincubated with the HRF-reactive C38-2 IgE, but not the HRF-nonreactive C48-2 IgE, in flow cytometry experiments (Figure 1C). However, we observed no HRF binding to C38-2 IgE-incubated FcERI ${ }^{-/-}$ BMMCs, which lack expression of the high-affinity IgE receptor FceRI. We also found that 9 of the 34 tested IgG $\mathrm{mAbs}$ bound to mHRF (Figure 1D). HRF binding was independent of IgG isotype or antigen specificity. For example, the HRF-binding IgG molecules JK31 and JK96, and the non-HRF binding IgG molecule JK116 all recognize the same viral antigen.

Importantly, an Fab, but not Fc, fragment of an HRF-binding IgG molecule bound mHRF (Figure 2, $A$ and $B$ ), and the IgE-HRF (or IgGHRF) interaction was inhibited by an $\mathrm{Fab}$, but not Fc, fragment (Figure 2, $\mathrm{C}-\mathrm{F})$. Consistent with this, the interaction between the OVA-specific $\alpha \mathrm{OE}$ $\operatorname{IgE}$ and $\mathrm{mHRF}$ was inhibited by OVA (Supplemental Figure 2A), and those between the trinitrophenyl-specific (TNP-specific) IGELa2 or C38-2 IgE and MHRF were inhibited by TNPglycine (Supplemental Figure 2, C and E). However, the IGELa2-mHRF and C38-2-mHRF interactions were not inhibited by TNP-glutamic acid (Supplemental Figure 2, C and E), and the C38-2-mHRF interaction was not inhibited by TNP-lysine, whereas the IGELa2-mHRF interaction was inhibited by TNP-lysine. These results suggest that the mHRF-binding site in IgE overlaps at least in part with the antigen-binding sites. Collectively, these results suggest that a considerable proportion of antibodies in immunized mice interact with HRF. In addition, 1 of the 5 tested human IgEs (i.e., HE-1) bound GST-mHRF (data not shown). 
A
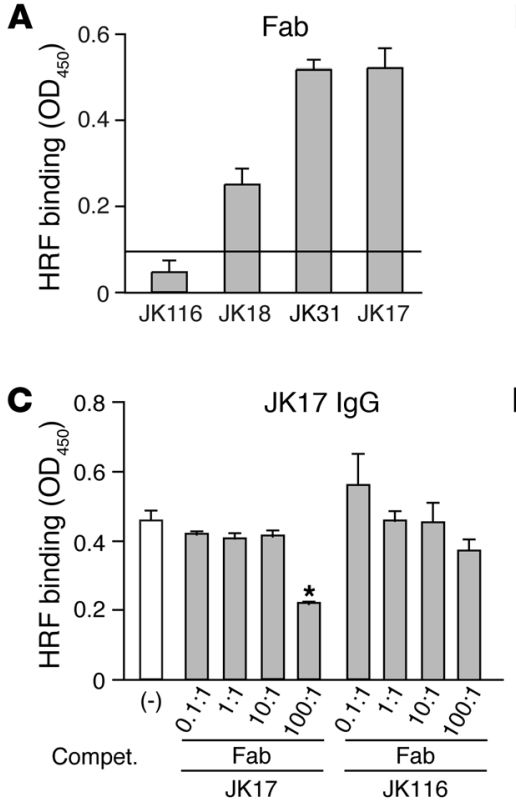

E

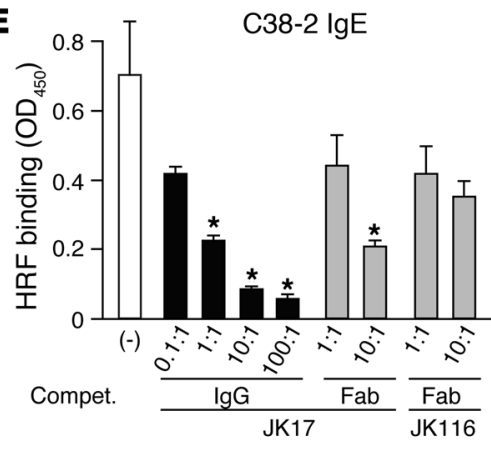

B

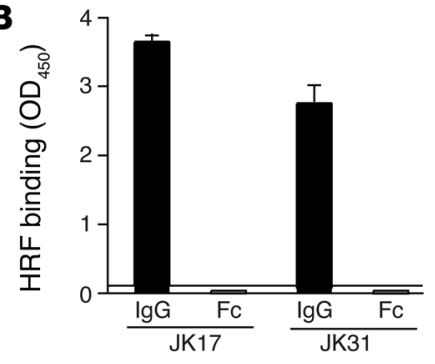

D

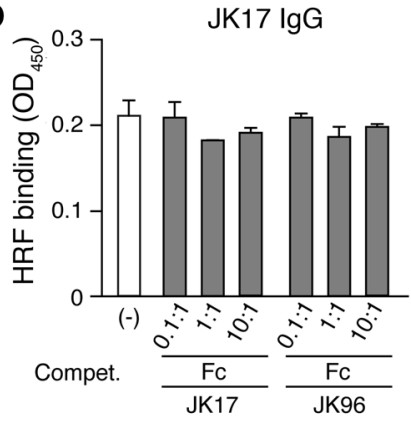

$\mathbf{F}$

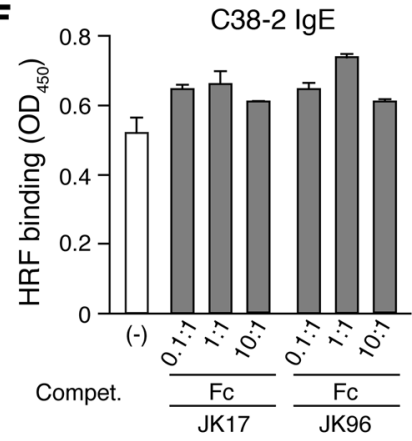

Figure 2

HRF-reactive Igs binds HRF via their Fab region. (A and B) Fab, but not Fc, fragments bound to HRF. GST-mHRF was coated onto a 96-well ELISA plate. After blocking with $10 \%$ FCS, the plate was incubated with whole molecules (IgG) or with Fab or Fc fragments of the indicated IgGs. HRF-bound Fab was detected by incubation with HRPconjugated goat anti-mouse $\kappa$ chain antibody. HRF-bound FC or IgG was detected with HRP-conjugated anti-lgG. (C and D) Competition by Fab, but not Fc, fragments for JK17 IgG binding to HRF. GST-mHRF was incubated with JK17 $\operatorname{lgG}$ in the presence or absence of Fab or Fc fragments at different molar ratios. Bound JK17 IgG was detected with HRP-conjugated anti-K (C) or biotin-conjugated anti-IgG1 followed by streptavidin-HRP (D). (E and F) Competition by Fab, but not Fc, fragments for C38-2 IgE binding to HRF. GST-mHRF was incubated with C38-2 IgE in the presence or absence of $\mathrm{Fab}$ or $\mathrm{Fc}$ fragments at different molar ratios. Bound IgE was detected with biotin-conjugated anti-mouse IgE followed by streptavidin-HRP. ${ }^{*} P<0.05$. All data are representative of 2 experiments.
Peptides corresponding to the Ig-binding sites within HRF inbibit HRF-Ig interactions. We next mapped the Ig-binding sites within HRF. IgE and IgG binding assays using a panel of truncated GST-mHRF proteins gave similar binding patterns (Figure 3, A and B, and Supplemental Figure 3). A major Ig-binding site was mapped to the N-terminal 19-residue peptide (N19), as GST-tagged N19 (referred to herein as GST-N19), but not GST fusion proteins containing shorter $\mathrm{N}$-terminal fragments, bound Igs. Another binding site was mapped to internal residues 79-142 (Figure 3, A and B). Further fine mapping localized the latter binding site to the $\mathrm{H} 3$ region (residues 107-135, termed GST-H3; Figure 3D and data not shown).

Intracellular HRF might contribute to allergic inflammation by controlling cell cycle progression, proliferation, and survival of immune and structural cells $(8,21,32)$. Therefore, it is essential to find an inhibitor of HRF-Ig interactions to dissect HRF's extracellular functions, separate from HRF's intracellular functions. We tested whether the Ig-interacting HRF sequences might serve as specific inhibitors of HRF binding to Igs. Indeed, GSTN19 inhibited IgE binding to mHRF with potency similar to fulllength GST-mHRF (Figure 3C). However, shorter mHRF peptides tested (residues 1-6, 1-12,1-16,5-19, and 9-19) or a scrambled peptide (KYI-N16) did not inhibit HRF-IgE binding (Supplemental Figure 4). Control experiments showed that GST-N19 did not affect growth properties that fall under the control of intracellular functions of HRF (8): treatment of various cells with 3.6 or $36 \mu \mathrm{M}$
GST-N19 did not affect their viability or proliferation (Supplemental Figure 5, A-D), nor did it affect apoptosis induced by growth factor withdrawal in BMMCs or by $\mathrm{H}_{2} \mathrm{O}_{2}$ in CHO-K1 cells (Supplemental Figure 5, E and F). These concentrations of HRF were higher than what has previously been shown to stimulate basophils (1.6-5 $\mu \mathrm{M}$; ref. 35). Importantly, GST-N19 did not enter BMMCs (Figure 4A). A synthetic N19 peptide also inhibited IgE binding to $\mathrm{MHRF}$ and did not alter the growth or survival of various cells (Supplemental Figure 6). Similar to GST-N19, GST-H3 also inhibited IgE binding to mHRF (Figure 3D); GST-H3 neither affected cell growth or apoptosis nor entered the cells (Supplemental Figure 7 and data not shown). These results indicated that the HRF N19 and H3 peptides can be used to probe extracellular functions of HRF in vitro and in vivo.

$\mathrm{N} 19$ and $\mathrm{H} 3$ peptides block mast cell activation. Analysis of purified recombinant mHRF-His ${ }_{6}$ on reducing and nonreducing SDS-PAGE yielded direct evidence for disulfide-linked dimerization of HRF (Supplemental Figure 8A). Both monomeric and dimeric forms of HRF could bind to IgE (data not shown). Consistent with this, monomeric mHRF mutant 2CA, with 2 cysteine residues at positions 28 and 172 substituted with alanine, also bound Igs (Supplemental Figure 9, A and B). The dimerizing ability of HRF with 2 Ig-binding sites suggests the potential of HRF to crosslink Ig-bound Fc receptors (Supplemental Figure $8 \mathrm{~B})$. This notion was supported by activation of mast cells by 
A

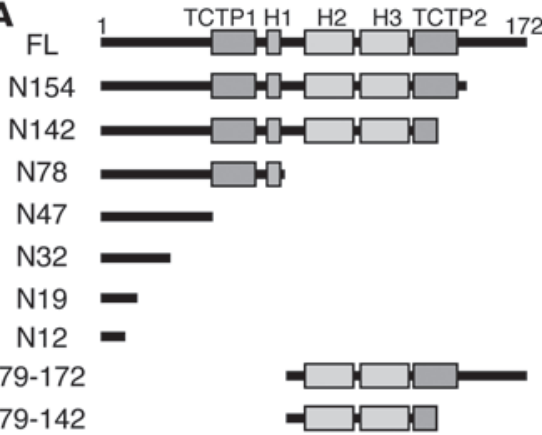

B
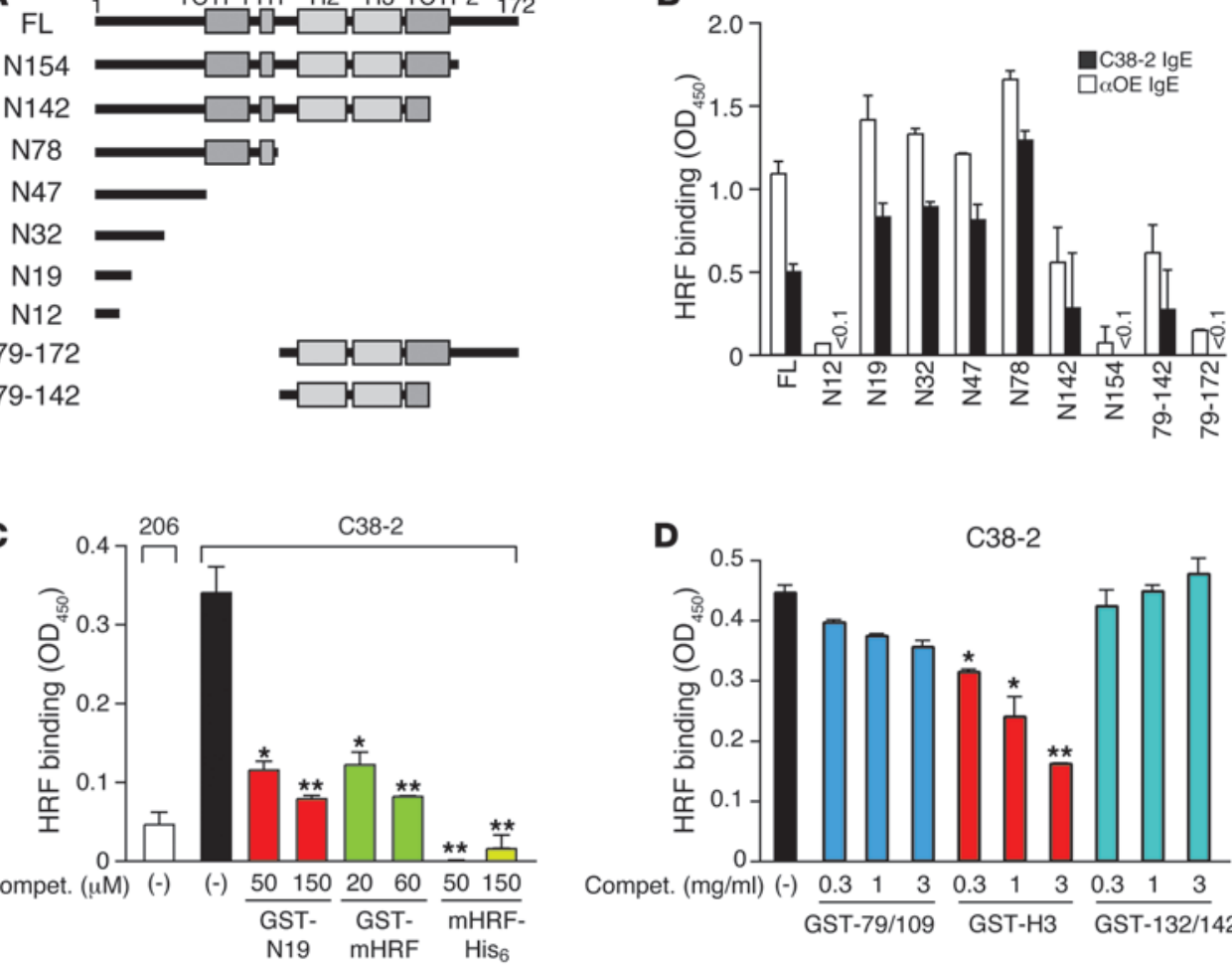

D

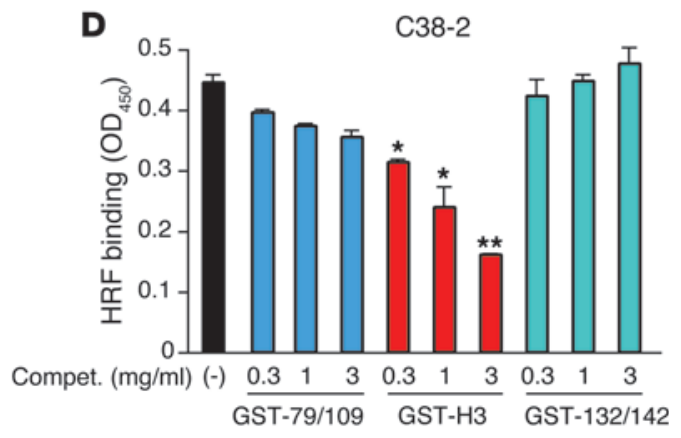

\section{Figure 3}

Mapping IgE-binding sites within HRF and inhibition of HRF-IgE interactions by the HRF-derived N19 and $\mathrm{H} 3$ peptides. (A) Scheme of full-length (FL) and truncated forms of GST-mHRF used for binding assays. Domain structures such as TCTP1-TCTP2 and $\mathrm{H} 1-\mathrm{H} 3$ are shown. (B) IgE-binding site mapping. C38-2 $(5 \mu \mathrm{g} / \mathrm{ml})$ and $\alpha \mathrm{OE}(20$ $\mu \mathrm{g} / \mathrm{ml}) \mathrm{lgE}$ molecules were incubated in wells coated with GST-mHRF. Bound Igs were detected by ELISA. $<0.1$, value too small to display. (C) Inhibition of HRF-Ig interactions by N19. IgE molecules were incubated in GST-mHRF-coated wells in the presence or absence of the indicated concentrations of competitors. After incubation, bound $\lg E$ was detected by ELISA. (D) Inhibition of HRF-Ig interactions by GST-H3. ${ }^{\star} P<0.05,{ }^{\star *} P<0.01$. Data are representative of 2 (B), 5 (C), or 3 (D) experiments. cotreatment with mHRF and HRF-reactive, but not HRF-nonreactive, IgEs, as evidenced by histamine release and cytokine production from BMMCs (Figure 4, B and C) and by $\beta$-hexosaminidase release from peritoneal mast cells (C38-2 IgE, $17.8 \% \pm 4.6 \%$ release; C48-2 IgE, $2.4 \% \pm 0.1 \%$ release; $P<0.0001)$. These reactions were inhibited by GST-N19 and GST-H3 (Figure 4, D and E, and data not shown). Consistent with mast cell activation, tyrosine phosphorylation of several proteins was observed in C38-2 IgE/HRF-treated cells (data not shown).

HRF inhibitors suppress passive cutaneous anaphylaxis. Acute passive cutaneous anaphylaxis (PCA) reactions induced by antigen in IgEsensitized mice are mediated mainly by histamine released from activated mast cells (36). LPRs in the skin are mediated in part by mast cell-derived TNF- $\alpha(37,38)$ and IL-33 (39). Strikingly, when HRF was injected i.d. 24 hours after IgE injection, both acute reactions and LPRs were induced by HRF-reactive, but not HRF-nonreactive, IgE (Figure 5, A and B). The HRF-reactive C38-2 $\operatorname{IgE}$ induced increased vascular permeability after HRF injection (Figure 5A). Interestingly, the LPRs induced by HRF, as measured by increased ear swelling at 6 hours, were as high as those induced by antigen (Figure 5B). Both acute reactions and LPRs induced by $\mathrm{IgE} / \mathrm{HRF}$ were prevented by pretreatment with GST-N19 (Figure $5 \mathrm{C}$ and data not shown) and appeared to be mast cell mediated, as the reactions were abolished in mast cell-deficient $\mathrm{Kit}^{\mathrm{W}-\mathrm{s} h / W-s h}$ mice (40) and restored in $\mathrm{Kit}^{W-s h / W-s h}$ mice engrafted with WT BMMCs (Figure 5A). Furthermore, loss of FceRI abolished PCA responses (Figure 5D). Control experiments showed little effect of GST or GST-N19 alone on ear thickness (data not shown). Therefore, HRF and HRF-reactive IgE can induce anaphylactic responses in a mast cell- and FceRI-dependent manner. Interestingly, PCA reactions were not induced by IgE/2CA mutant (Supplemental Figure 9, C and D), and IgE/HRF-induced PCA reactions were inhibited by
2CA mutant (Supplemental Figure 9E), which suggests that the dimeric form of HRF is responsible for the bioactivity of HRF.

We next tested whether HRF contributes to IgE/antigeninduced PCA reactions. Antigen was injected to the ears of IgEsensitized mice, with GST-N19 or GST pretreatment. GST-N19 significantly reduced PCA acute reactions and LPRs in mice sensitized with HRF-reactive IgE (Figure 5E and data not shown). However, PCA induced by an HRF-nonreactive IgE was insensitive to GST-N19 treatment. Similar results were observed using GSTH3 in place of GST-N19, and GST-N19 plus GST-H3 had a stronger PCA-suppressive effect than GST-N19 or GST-H3 alone (Supplemental Figure 10). These results suggest that HRF is required for maximal IgE/antigen-induced PCA reactions. Consistent with this, HRF was dramatically increased in the dermis during LPRs (Supplemental Figure 11).

HRF inhibitors suppress mast cell-dependent airway inflammation. Asthma is a chronic lung disease characterized by airway inflammation, airway hyperresponsiveness (AHR), and reversible airway obstruction (41). We used a mast cell-dependent, OVA-induced airway inflammation model (42). In addition to the increased HRF levels in lungs and blood (Figure 6A), immunofluorescence microscopy showed increased levels of HRF staining in nonpermeabilized lung tissues (Supplemental Figure 12A), which indicates that HRF is secreted into lung tissues in OVA-challenged mice. Levels of HRF-reactive IgG were also increased in plasma and BAL fluids of these mice (Supplemental Figure 12B). Pretreatment with GST-N19 before the OVA challenges abrogated airway inflammation, as evidenced by reduced eosinophils and neutrophils in BAL fluids (Figure 6B) and by reduced inflammatory cells and goblet cell hyperplasia in the lung (Figure 6C). Production of IL-13 (the cytokine essential for AHR, eosinophilia, and mucus production; refs. 43-45) and IL-5 (the cytokine critical for eosinophilia and 
A
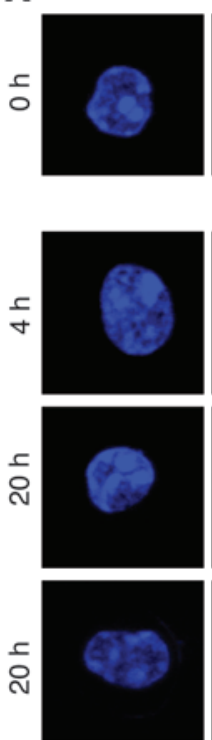

DAPI
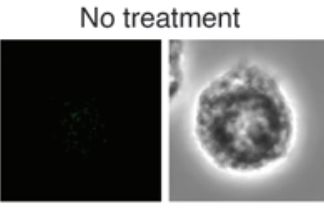

TAT-GST $200 \mu \mathrm{g} / \mathrm{ml}$

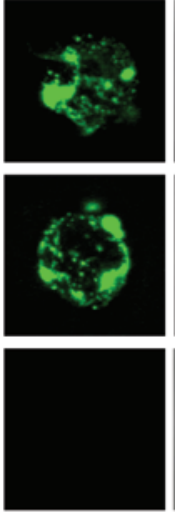

GST

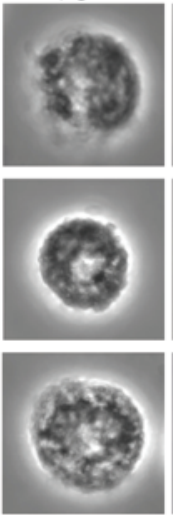

DIC
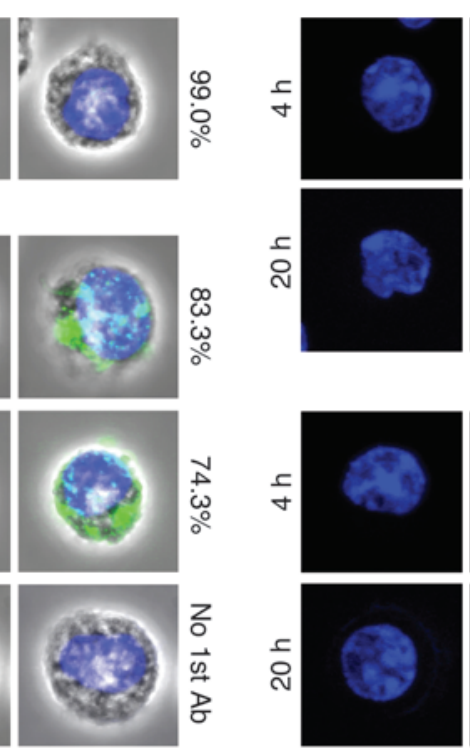

Merge
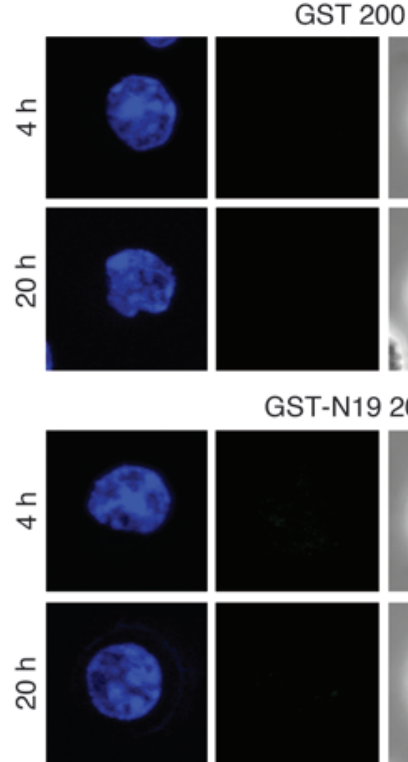

DAPI

\section{GST-N19 $200 \mu \mathrm{g} / \mathrm{ml}$}

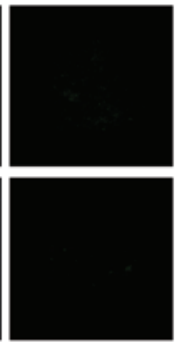

GST

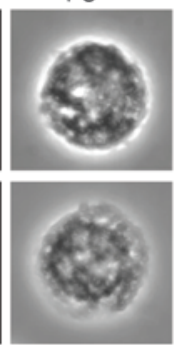

DIC
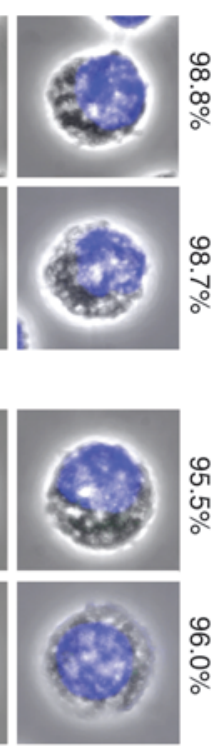

Merge

D
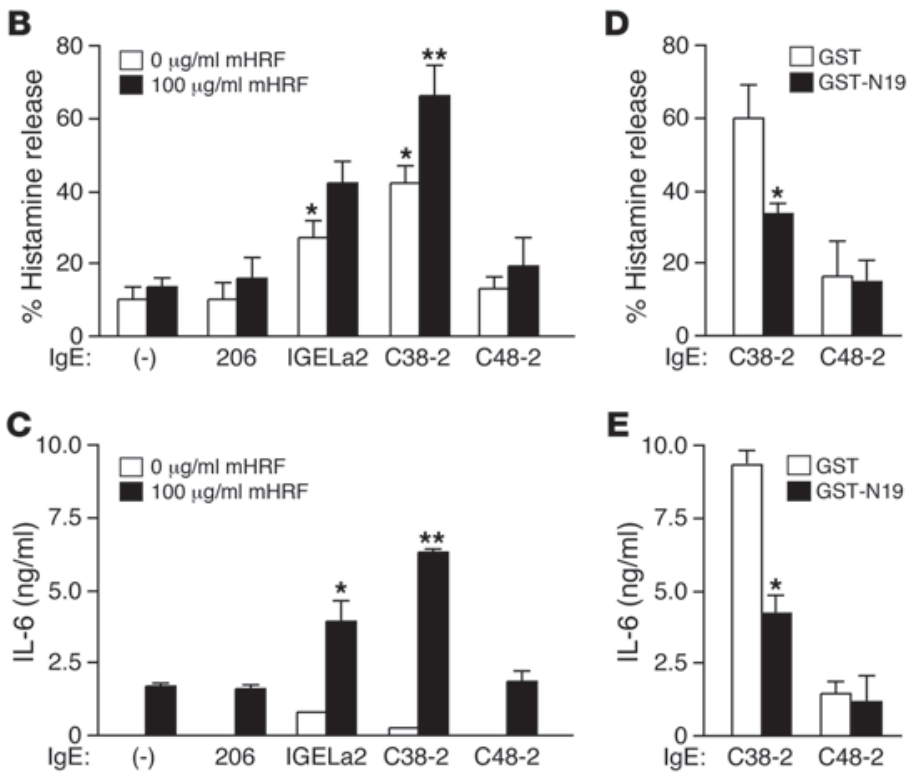

E

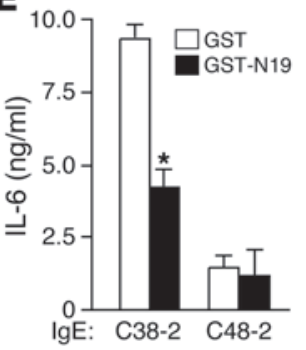

Figure 4

GST-N19 does not enter the cell interior and serves as an HRF inhibitor. (A) BMMCs were incubated with TAT-GST, GST, or GST-N19 protein for the indicated time periods at $37^{\circ} \mathrm{C}$. Washed cells were fixed, permeabilized, and stained with anti-GST followed by Alexa Fluor 488-conjugated anti-mouse IgG. Nuclei were stained with DAPI. Fluorescence was observed by confocal microscopy. DIC, differential interference contrast. Original magnification, $\times 150$. Percentages of the cells similar to the representative images are shown ( $\geq 150$ cells scored). (B and $\mathbf{C}$ ) BMMCs were incubated with $5 \mu \mathrm{g} / \mathrm{ml}$ of the indicated $\mathrm{IgE}$ and $100 \mu \mathrm{g} / \mathrm{ml} \mathrm{mHRF}$ for 45 minutes (histamine release) or 20 hours (IL-6 production). ( $\mathbf{D}$ and $\mathbf{E}) \mathrm{BMMCs}$ were incubated with $\lg \mathrm{E}$ and $\mathrm{mHRF}$ in the presence of $100 \mu \mathrm{M}$ GST or GSTN19. ${ }^{*} P<0.05$, ${ }^{* *} P<0.01$ versus respective control, Student's $t$ test. Data are representative of $3(\mathbf{A})$ or 2 (B-E) experiments.
AHR; ref. 46) in lung tissues was drastically decreased in GSTN19-treated mice (Figure 6D). Consistent with these observations, GST-N19 treatment inhibited AHR $(P<0.05$ vs. GST at $48 \mathrm{mg} / \mathrm{ml}$ methacholine, Bonferroni correction; Figure 6E). Circulating systemic HRF was reduced by GST-N19 (Supplemental Figure 12C), probably reflecting an antiinflammatory effect of GST-N19. In contrast, HRF-reactive plasma IgG levels and OVA-specific IgE, IgG1, and IgG2a levels were not affected by GST-N19 (Supplemental Figure 12B and data not shown). Administration of a synthetic N19 peptide or GST-H3 abrogated airway inflammation with similar potency to that of GST-N19 (Supplemental Figure 13 and data not shown).

We confirmed the efficacy of GST-N19 in a second model of asthma: partially IgE-dependent airway inflammation induced by Aspergillus fumigatus allergens (47). HRF inhibition resulted in substantial reduction of allergic airway inflammation and inflammatory cells in BAL fluids (Supplemental Figure 14). Interestingly, HRF inhibition failed to reduce airway inflammation in a mast cell-independent OVA-alum model (ref. 48 and Supplemental Figure 15).

HRF-induced airway inflammation is dependent on Fc receptors. Airway inflammation in the above experiments involves a complex interplay of various cells $(41,49,50)$. To gain mechanistic insights into how HRF promotes lung inflammation, we used a simpler in vivo model. Administration i.n. of WT, but not 2CA mutant, reduced/ carboxymethylated or boiled mHRF to WT naive mice induced weak but consistent lung inflammation, as shown by increased eosinophils, neutrophils, and macrophages/monocytes in BAL fluids (Figure 7A and data not shown). However, no or little HRFinduced lung inflammation was seen in B cell-deficient ( $\mu M T)$, mast cell-deficient $\left(K i t^{W-s b / W-s b}\right)$, or $F c R \gamma^{-/-}$mice (Figure 7, A and B). 
A
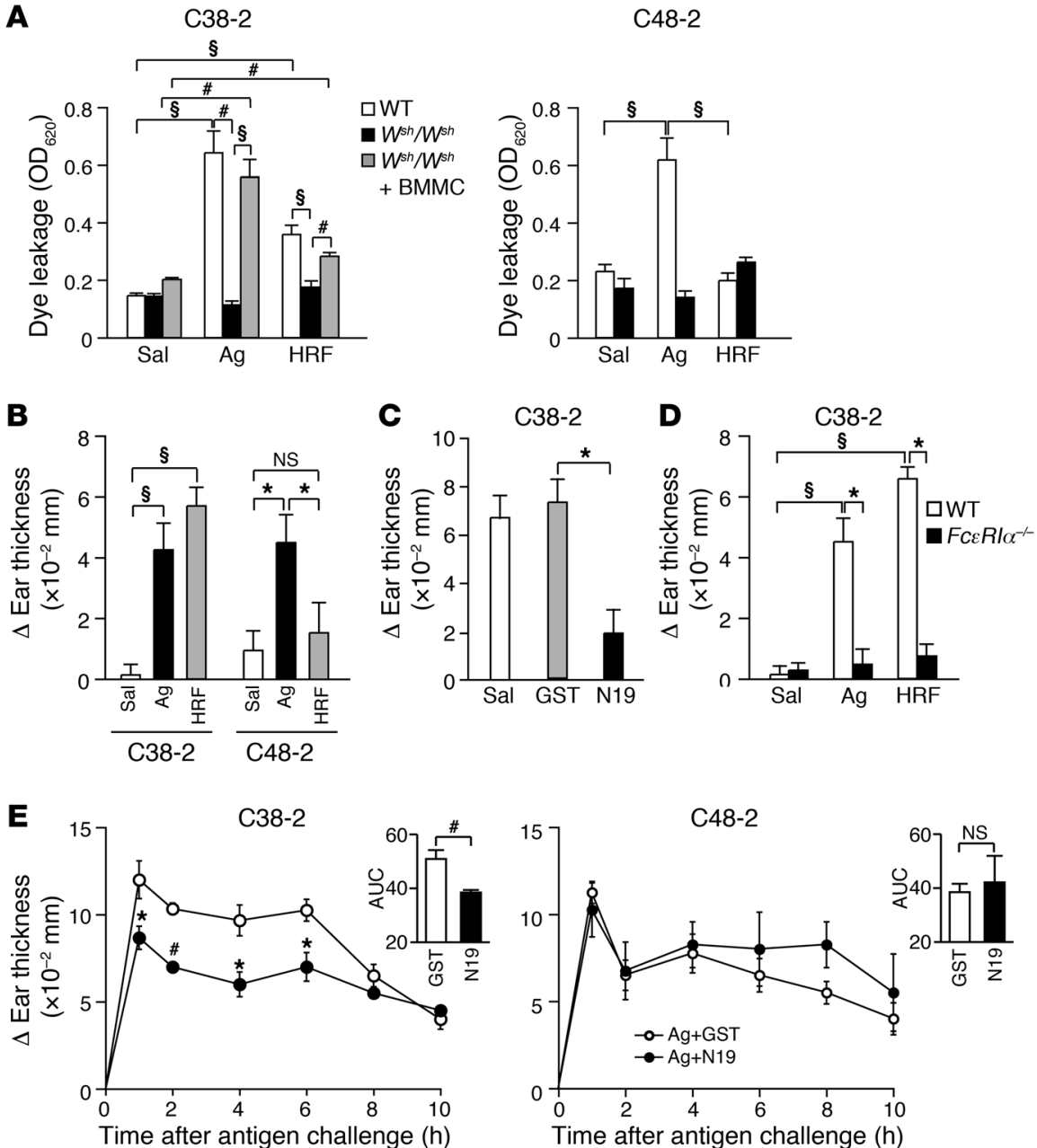

\section{Figure 5}

HRF promotes PCA reactions in mice sensitized with HRF-reactive IgE. (A) IgE/HRFinduced acute PCA reactions. Mice were sensitized with the indicated IgEs. 24 hours later, Evans blue and mHRF-His 6 were injected in IgE-sensitized mice. After 30 minutes, dye leakage from the ears was measured. For controls, saline (Sal) and $\mathrm{TNP}_{26}-\mathrm{BSA}(\mathrm{Ag})$ were injected in sensitized ears. $\mathrm{Kit}^{\mathrm{W} \text {-sh } / \mathrm{W} \text {-sh }}$ mice were used before or 6 weeks after engraftment of WT BMMCs by i.d. injection. Toluidine blue staining confirmed that the engrafted mice had numbers of mast cells similar to those of WT mice. (B-D) lgE/ HRF-induced PCA LPRs. mHRF-His 6 was injected in IgE-sensitized ears, and LPR was analyzed by measurement of ear thickness at 6 hours. For controls, saline and $\mathrm{TNP}_{26}{ }^{-}$ BSA were injected. (C) C38-2 IgE-sensitized mice were pretreated with saline, GST, or GST-N19 (N19) before injection with mHRF-His $_{6}$. (D) LPR in FceR/ $\alpha^{-/-}$mice. (E) Inhibition of IgE/antigen-induced PCA reactions by GST-N19. WT mice were sensitized overnight with the indicated IgEs. Left ears were injected with GST and right ears were injected with GST-N19, then TNP $_{26}$-BSA was injected in both ears. Ear thickness was measured. Insets show area under curve (AUC). ${ }^{\star} P<0.05,{ }^{\#} P<0.01,{ }^{\S} P<0.001$. 3-6 mice were used for each cohort. Data are representative of 2 (A-D) or $3(\mathbf{E})$ experiments.
FcR $\gamma$ is shared by multiple Fc receptors, including FceRI, Fc $\gamma \mathrm{RI}$, $\mathrm{Fc} \gamma \mathrm{RIII}$, and $\mathrm{F} c \gamma \mathrm{RIV}(51,52)$. Among the Igs and Fc receptors, IgE and FceRI were the predominant contributors to the effects of HRF, as HRF-induced lung inflammation was almost abrogated in naive $F c \varepsilon R I \alpha^{-/-}$mice (Figure 7A). Since FceRI is expressed on mast cells and basophils in mice (53), these results were consistent with the effectiveness of $\mathrm{N} 19$ and $\mathrm{H} 3$ peptides in mast cell-dependent asthma models (Figure 6 and data not shown).

Importantly, the absence of inflammatory cell responses to HRF in $\mu M T$ or $F c R \gamma^{-/-}$mice corroborated our finding that HRF bound Igs (Figure 1). To further evaluate the target range of HRF, we performed global gene expression analysis. Expression of 196 genes was up- or downregulated more than 3-fold by HRF in the lungs of naive WT mice, with 90 genes up- or downregulated more than 5 -fold (Figure 7C). Upregulated genes included those encoding Th1-, Th2-, and Th17-associated cytokines and various chemokines, potentially accounting for the recruitment of monocytes/ macrophages, neutrophils, eosinophils, and other immune cells (Supplemental Figure 16). Expression of some Th1 and Th2 cytokines were confirmed by real-time PCR analysis (data not shown). Other upregulated genes included the previously reported genes in mouse asthma models, such as Agr2, Ccl8, Ccl11, Fcgr2b, Scin, Serpina3g, Serpina3n, and Timp1. However, only a small fraction of these genes (39 of 196) fluctuated more than 3 -fold in
FceRI $\alpha^{-/-}$mice; furthermore, fewer genes (11 of 196) were changed in $\mathrm{FcR}^{-/-}$mice (Figure 7C). These results suggest that HRF executes its action largely, if not exclusively, by engaging IgE- and IgGbound $\mathrm{Fc}$ receptors and promotes airway inflammation.

\section{Discussion}

Despite considerable efforts in the last 15 years since the cloning of HRF (4), the receptor for HRF has not been identified. Using functional assays on RBL-2H3 rat mast cells expressing human FceRI, Wantke et al. indirectly suggested that human recombinant HRF does not bind to IgE (34). However, we clearly demonstrated that a subset of IgE and IgG can interact with HRF. Our study differs from that of Wantke et al., as theirs used human FceRI-expressing RBL-2H3 cells, which in our hands were difficult to activate. Importantly, we used more than a dozen IgE mAbs in an ELISAbased binding assay, compared with 2 types of polyclonal IgE used in the prior study. Furthermore, HRF binding of some IgE mAbs was confirmed by affinity pulldown and flow cytometry.

HRF interacts with the Fab, but not Fc, region of Igs. Experiments with OVA antigen and monovalent haptens suggested that the mHRF-binding site in IgE overlaps at least in part with the antigen-binding sites. Inspection of amino acid sequences of $\mathrm{V}$ regions of a limited number of IgE and IgG molecules indicates that HRF-reactive IgEs and IgGs contain unique $V_{k}$ sequences 
A
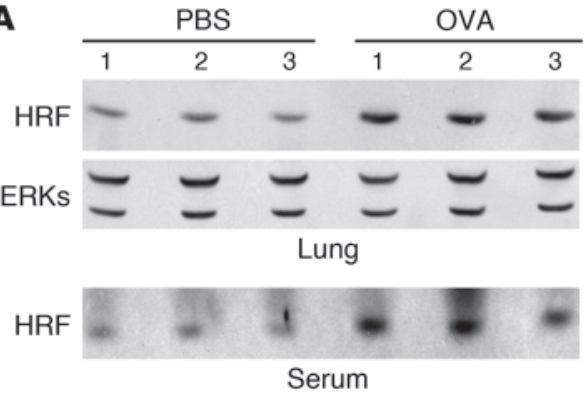

C

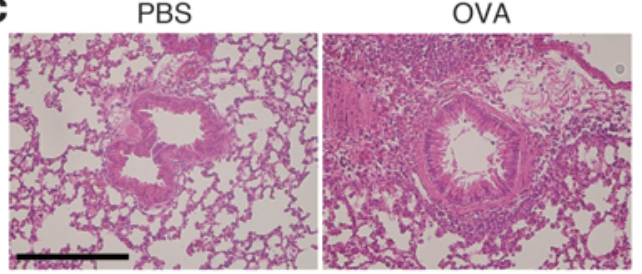

OVA + GST

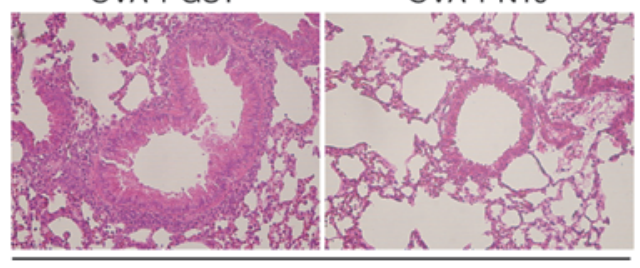

H\&E
B

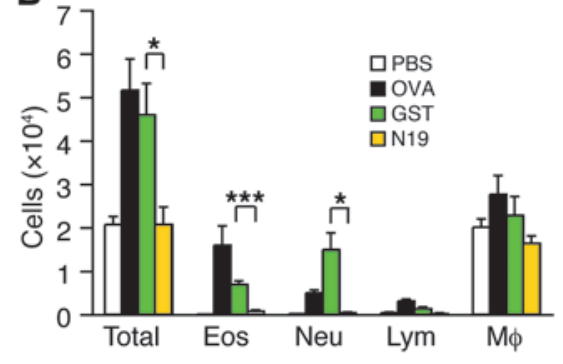

PBS
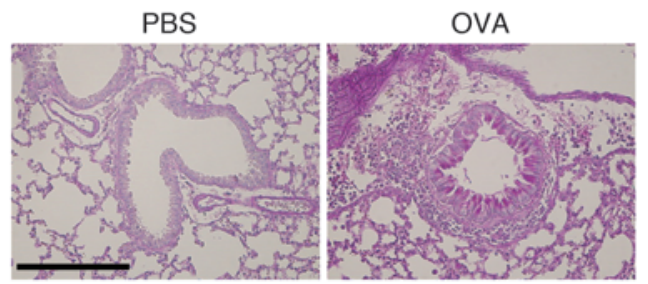

OVA + GST

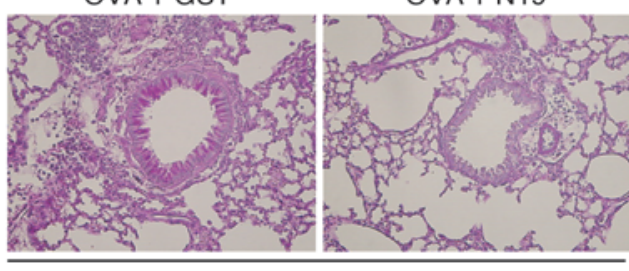

PAS
D

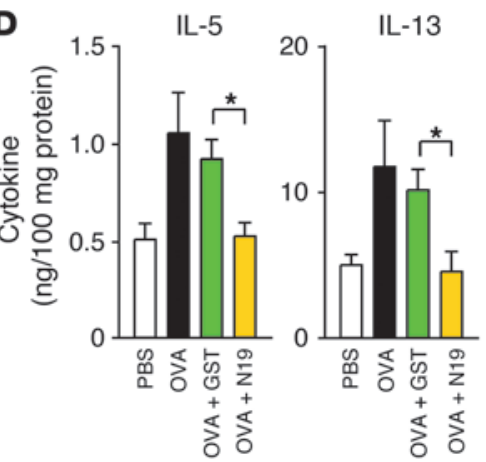

E $127-$ PBS

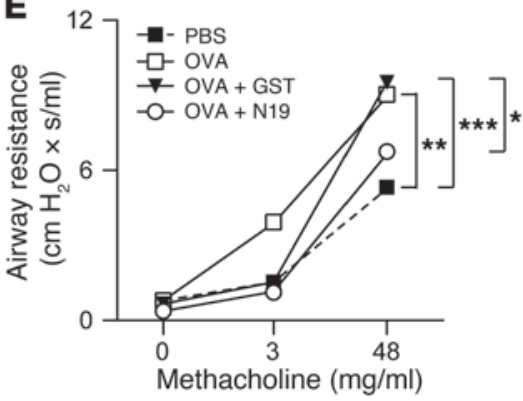

\section{Figure 6}

GST-N19 blocks mast celldependent airway inflammation. C57BL/6 mice were sensitized with OVA $(10 \mu \mathrm{g})$ and i.n. challenged with OVA (20 $\mu \mathrm{g})$ or PBS. Some mice were i.n. pretreated with GST or GST-N19 $(400 \mu \mathrm{g})$ before every OVA challenge. 24 hours after the last challenge, mice were subjected to invasive lung function testing, and BAL fluids and lung tissues were collected. (A) Increased HRF amounts in the lung and sera of OVA-sensitized and -challenged mice. SDS-PAGE was performed on lung homogenates and serum samples, and HRF amounts of 3 mice were evaluated by immunoblotting. ERK1/2 expression was used as a loading control. (B) Total and specific immune cell numbers in BAL fluids. Eos, eosinophils; Neu, neutrophils; Lym, lymphocytes; M $\phi$, macrophages and monocytes. (C) $\mathrm{H} \& \mathrm{E}$ and periodic acid-Schiff (PAS) staining of lung tissues. Scale bars: $200 \mu \mathrm{m}$. (D) IL-5 and IL-13 in lung homogenates were measured by ELISA. (E) Airway resistance was measured using FlexiVent. ${ }^{*} P<0.05$, ${ }^{* *} P<0.01,{ }^{* *} P<0.001 .3-6$ mice were used for each cohort. All data are representative of 3 experiments.
(8-30 and 2-137, respectively; Supplemental Table 1). In contrast, these IgEs and IgGs use different $\mathrm{V}_{\mathrm{H}}$ family members. The Ig-binding N19 peptide forms 2 antiparallel $\beta$-sheets (positions 3-5 and 14-15), which, together with the C-terminal $\beta$-sheet, form the 3 -stranded sheet B $(54,55)$. The structure consisting of sheet $\mathrm{B}$, the 4-stranded sheet $\mathrm{A}$, and the small helix is similar to that of the human protein Mss4, which binds to Rab proteins and is proposed to be a guanine nucleotide-free chaperone (56). The other Ig-interacting $\mathrm{H} 3$ domain is a long $\alpha$-helix packed against part of sheet $\mathrm{A}$. Our observations collectively suggest that 2 sites of HRF interact with $\mathrm{V}$ regions specifically. However, data on hapten inhibition of HRF-Ig interactions cannot rule out the possibility that HRF-Ig binding is enacted by relatively nonspecific ionic or other interactions of different parts of Igs.

As shown by others $(57,58)$, our bacterially expressed mHRF preparations can form a dimer. HRF has $2 \mathrm{Ig}$-binding sites at the $\mathrm{N} 19$ and H3 peptide regions. Our present biochemical analyses suggested that an HRF dimer can aggregate 2 or 4 FceRI complexes preloaded with IgE (Supplemental Figure 8B). As a dimer is the minimal FceRI complex required for cell activation (59), mHRF along with HRF-reactive IgE could induce mast cell activation. Consistent with these in vitro data, FceRI-dependent PCA-like skin inflammation and lung inflammation were induced by WT mHRF, but not the monomeric 2CA mutant mHRF.

The progress in HRF research has been hindered by the lack of identification of an HRF receptor and the lack of tools to distinguish its extracellular from intracellular HRF functions. The peptides N19 and H3 corresponding to the Ig-interacting sites within mHRF turned out to be specific inhibitors that interfered with the interactions between extracellular HRF and IgE, but had no effect on HRF's intracellular functions. The biologic activities of these peptides were shown by their suppression of in vitro mast cell activation and in vivo mast cell-dependent inflammation, i.e., PCA and airway inflammation. It should be emphasized that these peptides used as GST fusion proteins did not affect HRF's intracellular functions, as they were not taken up intracellulary. 


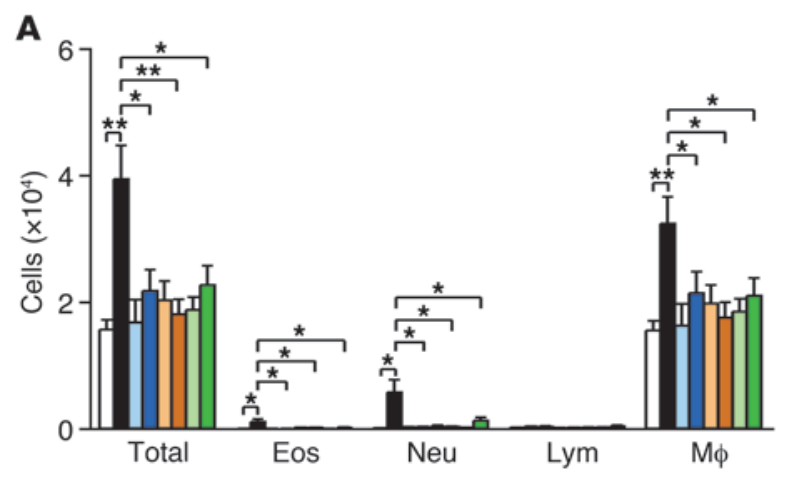

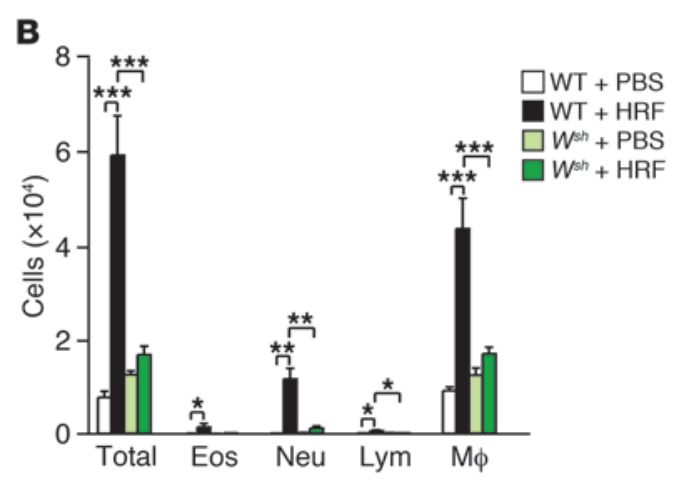
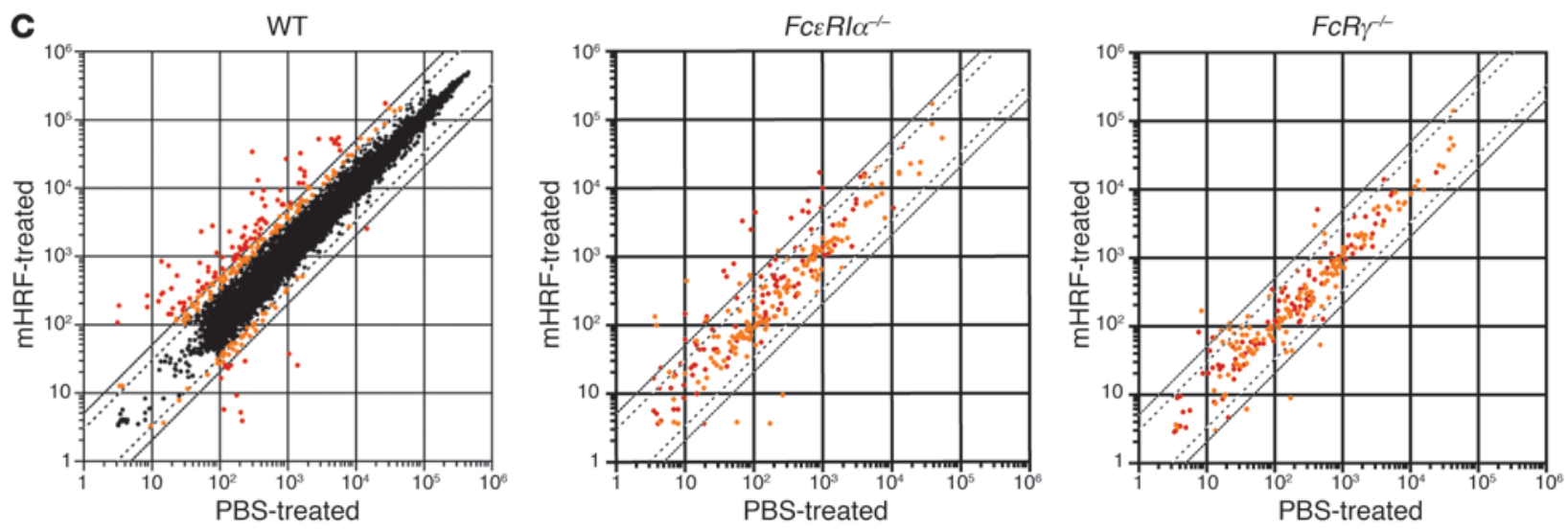

Figure 7

Lung inflammation is induced by HRF in naive mice in an Fc receptor-dependent manner. Naive WT C57BL/6 and mutant mice were treated i.n. with $40 \mu \mathrm{g}$ mHRF-His 6 3 times every third day. PBS served as a negative control. (A and B) HRF-induced lung inflammation required B and mast cells as well as $\mathrm{Fc \varepsilon RI}$ (and probably Fcy receptors). BAL procedures were conducted 24 hours after the last HRF administration. Differential cell counting was performed on cytospin preparations stained with May-Giemsa. (C) Genes whose expression was up- or downregulated by HRF. Black symbols, $\leq 3$-fold change; orange symbols, 3 - to 5 -fold change; red symbols, $>5$-fold change. Genes whose expression fluctuated $\leq 3$-fold

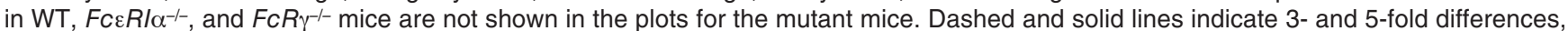
respectively, in gene expression. ${ }^{*} P<0.05,{ }^{* \star} P<0.01$, ${ }^{* \star} P<0.001$, Student's $t$ test. Each cohort consisted of $3-5$ mice. All data are representative of 5 (WT) and 2 (mutant) experiments.

A synthetic N19 peptide also did not affect the intracellular functions. Kim et al. have shown that N10 of HRF can work as a protein translocation domain (PTD) when fused with some proteins at their $\mathrm{N}$ termini (60). Protein internalization by this PTD was characterized by the high dose requirement $(8-32 \mu \mathrm{M})$ and slow kinetics compared with that of TAT, an HIV-encoded peptide (61). However, we found that the PTD function of N10 peptide in conjunction with GST (both N10-GST and GST-N10) was very weak compared with TAT-GST, particularly when N10 was fused at the C-terminus of GST (compare Supplemental Figure 7 and Figure 4A). More importantly, we clearly showed that GST-N19 and GST$\mathrm{H} 3$ did not enter the mast cell or other cells.

A recent study shows that an $\mathrm{N}$-terminal deletion mutant of rat HRF (Del-N11) exhibits a stronger dimerizing propensity and a stronger cytokine activity than the full-length HRF (58), consistent with our results indicating that the dimer is the biologically active form of HRF. The same study also shows that Del-N11 HRF, but not full-length HRF, induces airway inflammation, when the HRF protein is used to i.p. sensitize and then to i.n. challenge mice. Although these results are interesting, HRF was used as an antigen, similar to OVA in the acute airway inflammation experiments. Thus, the results do not necessarily represent the cytokine activity of HRF. Consistent with this interpretation, Del-N11 HRF fails to induce the recruitment of monocytes and macrophages in the acute airway inflammation experiments, which is very different from our data on airway inflammation induced by mHRF in naive mice.

Inhibition or amelioration of PCA and airway inflammation by N19 or H3 blockade of HRF-Ig interactions demonstrated that HRF plays a critical role in promoting antigen-induced inflammation. Consistent with our data, transgenic mice expressing HRF in a lung Clara cell-specific manner exhibit increased numbers of macrophages in BAL fluids in naive mice and increased airway inflammation in OVA-sensitized and OVA-challenged mice (62). However, the effect of HRF overexpression in this transgenic study could not be ascribed solely to the function of the secreted HRF molecule; the effect of the transgene could be due to the intracellular effect of HRF as well. Given our present data on the crucial role of HRF in asthma models, as well as the previous data of HRF-like activity in asthma and other allergic conditions, further studies of HRF and the utility of N19 and H3 inhibition of HRF are warranted in preclinical and clinical settings.

Airway inflammation by HRF in naive mice may be mediated predominantly by FceRI expressed on mast cells, but not basophils, as there are normal numbers of basophils in $\mathrm{Kit}^{\mathrm{W}-\mathrm{sh} / \mathrm{W}-\mathrm{sh}}$ mice 
(63). However, Fc receptors may also contribute to this inflammation. Abrogation of HRF-induced airway inflammation and gene modulation in naive $F c \varepsilon R I \alpha^{-/-}$and $F c R \gamma^{-/-}$mice support the notion that $\mathrm{IgE}$ and $\mathrm{IgG}$ are the long-sought receptors for HRF in the lung. Based on the profile of up- or downregulated genes, we propose the following scenario: HRF crosslinks FceRI-bound IgE (and $\mathrm{F}$ c receptor-bound IgG) on mast cells in naive mice and activates the cells; activated mast cells secrete various proinflammatory mediators; these mediators then initiate inflammation by directly or indirectly recruiting various inflammatory cells. In addition, a similar HRF-mediated mechanism promotes the amplification of allergen-induced inflammation by activating mast cells and basophils, in which FceRI complexes are occupied suboptimally with allergen-specific IgE (or, rather, occupied with nonspecific IgEs) to respond to allergen. Potentially at odds with the above scenario, sera and BAL fluids from naive mice contain HRF, which does not appear to induce inflammation under homeostatic conditions. Thus, there seem to be mechanisms to suppress inflammation potentially inducible by endogenous HRF. The endogenous amount of HRF might be lower than the threshold for HRF to induce inflammation. Alternatively, there might be endogenous inhibitors that inhibit HRF's extracellular functions. These possibilities are worthy of investigation.

In summary, our study demonstrated that the bioactive HRF (i.e., dimers and oligomers) interacted with some $\operatorname{IgE}$ molecules and could crosslink that IgE-bound FceRI. FceRI aggregates activated mast cells in vitro. Inhibitors that prevent HRF-Ig interactions suppressed IgE/antigen-induced skin hypersensitivity and allergen-induced mast cell-dependent airway inflammation. Thus, we conclude that HRF promotes allergic inflammation in the skin and lung.

\section{Methods}

Mice. C57BL/6 and Balb/c mice were purchased from the Jackson Laboratory. $F c \varepsilon R I \alpha^{-/-}, F c R \gamma^{-/-}$, and $\mu M T$ mice were also used.

Preparation of recombinant $m H R F$. $m$ HRF cDNAs were amplified by RT-PCR using the primers listed in Supplemental Table 2. GST fusion proteins were purified using glutathione-agarose (Sigma-Aldrich). mHRF-His $_{6}$ expressed by $\mathrm{pET}-24 \mathrm{a}(+)$ plasmid was purified using ProBond resin (Invitrogen). All recombinants were further purified by Sephacryl S-100 and dialyzed against PBS. mHRF-His 6 preparations contained less than $0.05 \mathrm{pg} / \mu \mathrm{g}$ protein of endotoxin, as measured by Limulus amebocyte lysate test.

ELISA. 96-well ELISA plates were coated overnight with GST, GST-mHRF, or mHRF-His $_{6}$ (each at $10 \mu \mathrm{g} / \mathrm{ml}$ in $0.1 \mathrm{M}$ carbonate buffer [ $\left.\mathrm{pH} 9.5\right]$ ). The plates were washed and blocked with $10 \%$ FCS or $1 \%$ BSA. Next, mouse IgE and IgG molecules (10 $\mu \mathrm{g} / \mathrm{ml})$, plasma (1:100-1:200 dilution), and BAL fluids (1:10 dilution) were incubated in the coated wells, after which bound $\mathrm{IgE}$ was detected by incubation with biotinylated anti-mouse IgE followed with HRP-conjugated streptavidin. Bound IgG was detected by incubation with HRP-conjugated anti-mouse IgG. Color was developed using TMB substrate (BD Biosciences), and absorbance at $450 \mathrm{~nm}$ was measured. Sources of IgE and IgG are listed in Supplemental Table 3.

Affinity pulldown of IgE with GST-mHRF. IgE mAbs $(3 \mu \mathrm{g})$ in $100 \mu \mathrm{l}$ of $1 \%$ Triton X-100/PBS were incubated with $10 \mu \mathrm{g}$ of GST- or GST-mHRF-agarose beads. Bead-bound IgEs were pulled down by centrifugation. IgE and GST proteins eluted with SDS sample buffer were detected by immunoblotting with anti-mouse IgE antibody and anti-GST mAb, respectively.

Binding affinity measurement by quartz crystal microbalance method. A quartz crystal microbalance-based (QCM-based) assay was performed using Affinix Q4 apparatus (Initium Co. Ltd.) as described previously (64).
Mast cells. BMMCs were generated by culturing bone marrow cells in IL-3 (65). Peritoneal mast cells purified using anti-c-Kit Positive Selection kit (StemCell Technologies) were also used.

Growth and apoptosis of cultured cells. CHO-K1, Jurkat, and Caco-2 cells were cultured in the absence or presence of GST or GST-N19 for 4 days, and live cells were counted. Apoptosis was induced by IL-3 depletion in BMMCs for 4 days and by $800 \mathrm{nM} \mathrm{H}_{2} \mathrm{O}_{2}$ in CHO-K1 cells for 2 days, and live cells were counted.

Microscopic localization of GST-N19 and other GST fusion proteins. BMMCs were incubated at $37^{\circ} \mathrm{C}$ with 20 or $200 \mu \mathrm{g} / \mathrm{ml}$ of GST or GST fusion proterin for $0-24$ hours. Washed cells were settled on glass slides. After fixation, cells were permeabilized with ice-cold methanol, then stained with anti-GST followed by Alexa Fluor 488-conjugated anti-mouse IgG. ProLong Gold antifade with DAPI (Invitrogen) was used to mount the slides. Fluorescence was observed with a FLUOVIEW FV10i confocal laser scanning microscope (Olympus).

Degranulation. Mast cells were sensitized overnight with IgE. The cells were stimulated with $\mathrm{TNP}_{26}-\mathrm{BSA}$ or mHRF-His ${ }_{6}$ for 45 minutes. The amount of histamine or $\beta$-hexosaminidase in supernatants was measured.

$P C A$. Mice were sensitized by i.d. injection of IgE into the ear with $0.5 \mu \mathrm{g}$ of IgE mAb. 24 hours later, Evans blue dye (i.v.) and mHRF-His ${ }_{6}(10 \mu \mathrm{g}$, i.d.) were sequentially injected. Dye extravasated 30 minutes after mHRF challenge was measured by extracting ears in formamide. Engraftment of $K i t^{W-s b / W-s h}$ mice with BMMCs was performed 6 weeks before the experiments (66). In some experiments in which mice were stimulated without Evans blue, ear thickness was measured.

Asthma models. In the first model (42), C57BL/6 mice were sensitized with i.p. injection of OVA $(10 \mu \mathrm{g})$ at days $0,7,14,21,28$, and 35 . At days 40, 43, and 46 , mice were i.n. challenged with OVA $(20 \mu \mathrm{g})$. Some mice were i.n. pretreated with 40-400 $\mu$ g of GST or GST-N19 before every OVA challenge. In some experiments, $20 \mu \mathrm{g}$ of synthetic N19 peptide or vehicle (2\% DMSO) was used for pretreatment. 24 hours after the last challenge, lung function was tested using FlexiVent system (SCIREQ). Mice were sacrificed, and BAL fluids as well as blood and lung tissues were collected. Cells in BAL fluids were enumerated after staining with May-Giemsa. Paraffin-embedded lung tissues were stained with $\mathrm{H} \& \mathrm{E}$ and periodic acid-Schiff. Cytokines in lung homogenates were quantified by ELISA.

In the second model of asthma (47), BALB/c mice were i.n. treated with Aspergillus fumigatus allergen ( $50 \mu \mathrm{l}$; Greer Laboratories) or PBS 3 times per week for 3 weeks. Some mice were i.n. pretreated with GST or GST-N19 $(200 \mu \mathrm{g} / 50 \mu \mathrm{l})$ beginning at the second week for 30 minutes before each immunization. 24 hours after the last challenge, mice were sacrificed.

In the third model (48), C57BL/6 mice were i.p. immunized with OVA in the presence of alum on days 0 and 12 . Mice were i.n. administered with OVA $(20 \mu \mathrm{g} / 20 \mu \mathrm{l})$ on days 24,26 , and 28 . Some mice were i.n. pretreated with GST or GST-N19 $(400 \mu \mathrm{g} / 20 \mu \mathrm{l})$ before each OVA challenge. 24 hours after the last challenge, mice were sacrificed.

Oligonucleotide microarray. Total RNA was extracted from lungs using RNeasy Total RNA Mini Kit (Qiagen). A microarray analysis was performed using 200 ng of total RNA from each sample and SurePrint G3 Mouse Gene Expression $8 \mathrm{x} 60 \mathrm{~K}$ arrays (Agilent Technologies) according to the manufacturer's instructions. The microarray data have been deposited in Gene Expression Omnibus (GEO; accession no. GSE34133; http://www.ncbi.nlm.nih.gov/geo/query/acc. cgi?acc=GSE34133). Data analysis was performed with GeneSpring software (version GX 10.3). Because the expression levels of housekeeping genes (GAPDH and $\beta$-actin) did not differ among all samples, specific normalization was not performed. To eliminate genes containing only a background signal, genes were selected only if the raw values of "Expression" were more than 100. In addition, we focused on probes with reliable annotations (https://earray. chem.agilent.com/earray/) in the present study. A total of 16,374 genes met these criteria and were subjected to further analysis. 
Statistics. Bonferroni correction was used for AHR analysis. Other statistical analyses were performed by 2-tailed Student's $t$ test. Data shown indicate mean \pm SEM. A $P$ value less than 0.05 was considered significant.

Study approval. Animal experiments were approved by the Animal Care and Use Committee of the La Jolla Institute for Allergy and Immunology.

\section{Acknowledgments}

We thank Jae-Youn Cho and Peter Rosenthal for superb technical assistance and Shane Crotty and Howard M. Grey for critically reading this manuscript. This study was supported in part by grants from the NIH (to T. Kawakami) and the National Institute of Biomedical Innovation (ID10-43; to K. Matsumoto). This is Publication 1262 from the La Jolla Institute for Allergy and Immunology.

1. Galli SJ, Kalesnikoff J, Grimbaldeston MA, Piliponsky AM, Williams CM, Tsai M. Mast cells as "tunable" effector and immunoregulatory cells: recent advances. Annu Rev Immunol. 2005;23:749-786.

2. Thueson DO, Speck LS, Lett-Brown MA, Grant JA. Histamine-releasing activity (HRA). I. Production by mitogen- or antigen-stimulated human mononuclear cells. J Immunol. 1979;123(2):626-632.

3. MacDonald SM. Histamine releasing factors. In: Razin E, Rivera J, eds. Signal Transduction in Mast Cells and Basophils. New York, New York, USA: SpringerVerlag; 1999:390-401.

4. MacDonald SM, Rafnar T, Langdon J, Lichtenstein LM. Molecular identification of an IgE-dependent histamine-releasing factor. Science. 1995; 269(5224):688-690.

5. Bohm H, et al. The growth-related protein P23 of the Ehrlich ascites tumor: translational control, cloning and primary structure. Biochem Int. 1989; 19(2):277-286.

6. Chitpatima ST, Makrides S, Bandyopadhyay R, Brawerman G. Nucleotide sequence of a major messenger RNA for a 21 kilodalton polypeptide that is under translational control in mouse tumor cells. Nucleic Acids Res. 1988;16(5):2350.

7. Li F, Zhang D, Fujise K. Characterization of fortilin, a novel antiapoptotic protein. $J$ Biol Chem. 2001;276(50):47542-47549.

8 . Bommer UA, Thiele BJ. The translationally controlled tumour protein (TCTP). Int J Biochem Cell Biol. 2004;36(3):379-385.

9. MacDonald SM. Histamine-releasing factors. Curr Opin Immunol. 1996;8(6):778-783.

10. Warner JA, Pienkowski MM, Plaut M, Norman PS, Lichtenstein LM. Identification of histamine releasing factor(s) in the late phase of cutaneous IgE-mediated reactions. J Immunol. 1986;136(7):2583-2587.

11. MacDonald SM, et al. Studies of IgE-dependent histamine releasing factors: heterogeneity of $\operatorname{IgE}$. J Immunol. 1987;139(2):506-512.

12. MacDonald SM. Histamine Releasing Factors And Ige Heterogeneity. St Louis, Missouri, USA: Mosby-Year Book Inc; 1993.

13. Telerman A, Amson R. The molecular programme of tumour reversion: the steps beyond malignant transformation. Nat Rev Cancer. 2009;9(3):206-216.

14. Thiele H, Berger M, Skalweit A, Thiele BJ. Expression of the gene and processed pseudogenes encoding the human and rabbit translationally controlled tumour protein (TCTP). Eur J Biochem. 2000; 267(17):5473-5481.

15. Guillaume E, et al. Cellular distribution of translationally controlled tumor protein in rat and human testes. Proteomics. 2001;1(7):880-889.

16. Bommer UA, et al. The mRNA of the translationally controlled tumor protein P23/TCTP is a highly structured RNA, which activates the dsRNA-dependent protein kinase PKR. RNA. 2002;8(4):478-496.

17. Tuynder $\mathrm{M}$, et al. Biological models and genes of
Received for publication May 18, 2011, and accepted in revised form October 12, 2011.

Address correspondence to: Toshiaki Kawakami, Division of Cell Biology, La Jolla Institute for Allergy and Immunology, 9420 Athena Circle, La Jolla, California 92037, USA. Phone: 858.752.6814; Fax: 858.752.6986; E-mail: toshi@liai.org.

Miho Kimura's present address is: Department of Rheumatology and Infectious Diseases, Kitasato University School of Medicine, Sagamihara, Japan.

Jiro Kitaura's present address is: Division of Cellular Therapy, Institute of Medical Science, University of Tokyo, Tokyo, Japan. tumor reversion: cellular reprogramming through tpt1/TCTP and SIAH-1. Proc Natl Acad Sci U S A. 2002;99(23):14976-14981.

18. Cans C, et al. Translationally controlled tumor protein acts as a guanine nucleotide dissociation inhibitor on the translation elongation factor eEF1A. Proc Natl Acad Sci U S A. 2003;100(24):13892-13897.

19. Fleischer TC, Weaver CM, McAfee KJ, Jennings JL, Link AJ. Systematic identification and functional screens of uncharacterized proteins associated with eukaryotic ribosomal complexes. Genes Dev. 2006; 20(10):1294-1307.

20. Langdon JM, Vonakis BM, MacDonald SM. Identification of the interaction between the human recombinant histamine releasing factor/translationally controlled tumor protein and elongation factor-1 delta (also known as eElongation factor-1B beta). Biochim Biophys Acta. 2004;1688(3):232-236.

21. Hsu YC, Chern JJ, Cai Y, Liu M, Choi KW. Drosophila TCTP is essential for growth and proliferation through regulation of dRheb GTPase. Nature. 2007;445(7129):785-788.

22. Dong X, Yang B, Li Y, Zhong C, Ding J. Molecular basis of the acceleration of the GDP-GTP exchange of human ras homolog enriched in brain by human translationally controlled tumor protein. J Biol Chem. 2009;284(35):23754-23764

23. Zhang D, Li F, Weidner D, Mnjoyan ZH, Fujise K. Physical and functional interaction between myeloid cell leukemia 1 protein (MCL1) and Fortilin. The potential role of MCL1 as a fortilin chaperone. J Biol Chem. 2002;277(40):37430-37438.

24. Liu H, Peng HW, Cheng YS, Yuan HS, Yang-Yen HF. Stabilization and enhancement of the antiapoptotic activity of mcl-1 by TCTP. Mol Cell Biol. 2005;25(8):3117-3126.

25. Yang $\mathrm{Y}$, et al. An $\mathrm{N}$-terminal region of translationally controlled tumor protein is required for its antiapoptotic activity. Oncogene. 2005;24(30):4778-4788.

26. Susini L, et al. TCTP protects from apoptotic cell death by antagonizing bax function. Cell Death Differ. 2008;15(8):1211-1220.

27. Rho SB, et al. Anti-apoptotic protein TCTP controls the stability of the tumor suppressor p53. FEBS Lett. 2011;585(1):29-35.

28. Gachet Y, Tournier S, Lee M, Lazaris-Karatzas A, Poulton T, Bommer UA. The growth-related, translationally controlled protein P23 has properties of a tubulin binding protein and associates transiently with microtubules during the cell cycle. J Cell Sci. 1999;112(pt 8):1257-1271.

29. Fenner BJ, Scannell M, Prehn JH. Expanding the substantial interactome of NEMO using protein microarrays. PLoS One. 2010;5(1):e8799.

30. Rid R, et al. H2O2-dependent translocation of TCTP into the nucleus enables its interaction with VDR in human keratinocytes: TCTP as a further module in calcitriol signalling. J Steroid Biochem Mol Biol. 2010;118(1-2):29-40.
31. Yarm FR. Plk phosphorylation regulates the microtubule-stabilizing protein TCTP. Mol Cell Biol. 2002;22(17):6209-6221.

32. Chen SH, et al. A knockout mouse approach reveals that TCTP functions as an essential factor for cell proliferation and survival in a tissue- or cell type-specific manner. Mol Biol Cell. 2007;18(7):2525-2532.

33. Koide Y, et al. Embryonic lethality of fortilin-null mutant mice by BMP-pathway overactivation. Biochim Biophys Acta. 2009;1790(5):326-338.

34. Wantke F, MacGlashan DW, Langdon JM, MacDonald SM. The human recombinant histamine releasing factor: functional evidence that it does not bind to the IgE molecule. J Allergy Clin Immunol. 1999; 103(4):642-648.

35. Langdon JM, Schroeder JT, Vonakis BM, Bieneman AP, Chichester K, Macdonald SM. Histamine-releasing factor/translationally controlled tumor protein (HRF/TCTP)-induced histamine release is enhanced with SHIP-1 knockdown in cultured human mast cell and basophil models. J Lenkoc Biol. 2008; 84(4):1151-1158.

36. Inagaki N, Goto S, Yamasaki M, Nagai H, Koda A. Studies on vascular permeability increasing factors involved in 48-hour homologous PCA in the mouse ear. Int Arch Allergy Appl Immunol. 1986; 80(3):285-290

37. Wershil BK, Wang ZS, Gordon JR, Galli SJ. Recruitment of neutrophils during IgE-dependent cutaneous late phase reactions in the mouse is mast celldependent. Partial inhibition of the reaction with antiserum against tumor necrosis factor-alpha. J Clin Invest. 1991;87(2):446-453.

38. Nagai H, et al. TNF-alpha participates in an IgEmediated cutaneous reaction in mast cell deficient, WBB6F1-W/Wv mice. Inflamm Res. 1996; 45(3):136-140.

39. Hsu CL, Neilsen CV, Bryce PJ. IL-33 is produced by mast cells and regulates IgE-dependent inflammation. PLoS One. 2010;5(8):e11944.

40. Metz M, Grimbaldeston MA, Nakae S, Piliponsky AM, Tsai M, Galli SJ. Mast cells in the promotion and limitation of chronic inflammation. Immunol Rev. 2007;217:304-328.

41. Wills-Karp M. Immunologic basis of antigeninduced airway hyperresponsiveness. Annu Rev Immunol. 1999;17:255-281.

42. Williams CM, Galli SJ. Mast cells can amplify airway reactivity and features of chronic inflammation in an asthma model in mice. J Exp Med. 2000; 192(3):455-462.

43. Wills-Karp M, et al. Interleukin-13: central mediator of allergic asthma. Science. 1998;282(5397):2258-2261.

44. Grunig G, et al. Requirement for IL-13 independently of IL-4 in experimental asthma. Science. 1998;282(5397):2261-2263.

45. Walter DM, et al. Critical role for IL-13 in the development of allergen-induced airway hyperreactivity. JImmunol. 2001;167(8):4668-4675. 
46. Foster PS, Hogan SP, Ramsay AJ, Matthaei KI, Young IG. Interleukin 5 deficiency abolishes eosinophilia, airways hyperreactivity, and lung damage in a mouse asthma model. J Exp Med. 1996;183(1):195-201.

47. Mathias CB, et al. IgE influences the number and function of mature mast cells, but not progenitor recruitment in allergic pulmonary inflammation. J Immunol. 2009;182(4):2416-2424.

48. Takeda K, et al. Development of eosinophilic airway inflammation and airway hyperresponsiveness in mast cell-deficient mice. J Exp Med. 1997; 186(3):449-454.

49. Kim HY, DeKruyff RH, Umetsu DT. The many paths to asthma: phenotype shaped by innate and adaptive immunity. Nat Immunol. 2010;11(7):577-584.

50. Locksley RM. Asthma and allergic inflammation. Cell. 2010;140(6):777-783.

51. Ravetch JV, Bolland S. IgG Fc receptors. Annu Rev Immunol. 2001;19:275-290.

52. Nimmerjahn F, Bruhns P, Horiuchi K, Ravetch JV. FcgammaRIV: a novel FcR with distinct IgG subclass specificity. Immunity. 2005;23(1):41-51.

53. Turner H, Kinet JP. Signalling through the highaffinity IgE receptor Fc epsilonRI. Nature. 1999; 402(6760 suppl):B24-B30.

54. Thaw P, Baxter NJ, Hounslow AM, Price C, Waltho
JP, Craven CJ. Structure of TCTP reveals unexpected relationship with guanine nucleotide-free chaperones. Nat Struct Biol. 2001;8(8):701-704.

55. Hinojosa-Moya J, Xoconostle-Cazares B, PiedraIbarra E, Mendez-Tenorio A, Lucas WJ, RuizMedrano R. Phylogenetic and structural analysis of translationally controlled tumor proteins. J Mol Evol. 2008;66(5):472-483.

56. Nuoffer C, Wu SK, Dascher C, Balch WE. Mss4 does not function as an exchange factor for Rab in endoplasmic reticulum to Golgi transport. Molecular biology of the cell. 1997;8(7):1305-1316.

57. Yoon T, Jung J, Kim M, Lee KM, Choi EC, Lee K. Identification of the self-interaction of rat TCTP/ IgE-dependent histamine-releasing factor using yeast two-hybrid system. Arch Biochem Biophys. 2000; 384(2):379-382.

58. Kim M, et al. Dimerization of translationally controlled tumor protein is essential for its cytokinelike activity. PLoS One. 2009;4(7):e6464.

59. Segal DM, Taurog JD, Metzger H. Dimeric immunoglobulin E serves as a unit signal for mast cell degranulation. Proc Natl Acad Sci U S A. 1977; 74(7):2993-2997.

60 . Kim M, et al. A protein transduction domain located at the NH2-terminus of human translationally controlled tumor protein for delivery of active molecules to cells. Biomaterials. 2011;32(1):222-230.

61. Nagahara H, et al. Transduction of full-length TAT fusion proteins into mammalian cells: TATp27Kip1 induces cell migration. Nat Med. 1998; 4(12):1449-1452.

62. Yeh YC, et al. The effects of overexpression of histamine releasing factor (HRF) in a transgenic mouse model. PLoS One. 2010;5(6):e11077.

63. Grimbaldeston MA, Chen CC, Piliponsky AM, Tsai M, Tam SY, Galli SJ. Mast cell-deficient W-sash c-kit mutant Kit W-sh/W-sh mice as a model for investigating mast cell biology in vivo. Am J Pathol. 2005;167(3):835-848.

64. Ozeki T, et al. Surface-bound casein modulates the adsorption and activity of kinesin on $\mathrm{SiO} 2$ surfaces. Biophys J. 2009;96(8):3305-3318.

65. Kawakami T, et al. Tyrosine phosphorylation is required for mast cell activation by Fc epsilon RI cross-linking. J Immunol. 1992;148(11):3513-3519.

66. Nakano T, et al. Fate of bone marrow-derived cultured mast cells after intracutaneous, intraperitoneal, and intravenous transfer into genetically mast cell-deficient $\mathrm{W} / \mathrm{Wv}$ mice. Evidence that cultured mast cells can give rise to both connective tissue type and mucosal mast cells. JExp Med. 1985;162(3):1025-1043. 